\title{
Challenges and Opportunities for Communication about the Role of Genomics in Public Health
}

\author{
Caitlin G. Allen $^{\text {a }}$ Ridgely Fisk Green ${ }^{\mathrm{b}}$ Scott Bowen ${ }^{\mathrm{b}}$ W. David Dotson ${ }^{\mathrm{b}}$ \\ Wei Yu ${ }^{b}$ Muin J. Khoury ${ }^{b}$ \\ aDepartment of Behavioral, Social, and Health Education Sciences, Rollins School of Public Health, Emory University, \\ Atlanta, GA, USA; b Office of Genomics and Precision Public Health, Office of Science, Centers for Disease Control and \\ Prevention, Atlanta, GA, USA
}

\section{Keywords}

Communication · Genomics · Medicine · Public health

\begin{abstract}
Despite growing awareness about the potential for genomic information to improve population health, lingering communication challenges remain in describing the role of genomics in public health programs. Identifying and addressing these challenges provide an important opportunity for appropriate communication to ensure the translation of genomic discoveries for public health benefits. In this commentary, we describe 5 common communication challenges encountered by the Centers for Disease Control and Prevention's Office of Genomics and Precision Public Health based on over 20 years of experience in the field. These include (1) communicating that using genomics to assess rare diseases can have an impact on public health; (2) providing evidence that genetic factors can add important information to environmental, behavioral, and social determinants of health; (3) communicating that although genetic factors are nonmodifiable, they can increase the impact of public health programs and communication strategies; (4) addressing the concern that genomics is not ready for clinical practice; and
\end{abstract}

(5) communicating that genomics is valuable beyond the domain of health care and can be integrated as part of public health programs. We discuss opportunities for addressing these communication challenges and provide examples of ongoing approaches to communication about the role of genomics in public health to the public, researchers, and practitioners.

(c) 2021 S. Karger AG, Basel

\section{Introduction}

Genomics has been successfully integrated into public health initiatives, including newborn screening, efforts to detect and treat hereditary cancers, and in Healthy People 2020 and 2030 objectives $[1,2]$. Although genomics has not yet led to widespread changes in clinical and public health practice, as a field, genomics has already yielded important public health benefits. These include efforts to identify the 1 to 3 million people in the USA with hereditary breast and ovarian cancer (HBOC), Lynch syndrome (LS), and familial hypercholesterolemia (FH) through cascade screening and other precision public health approaches [3]. Nevertheless, a substantial trans-

karger@karger.com

(c) 2021 S. Karger AG, Basel

www.karger.com/phg

Karger!
Muin J. Khoury

Office of Genomics and Precison Public Health

Office of Science, Centers for Disease Control and Prevention

4770 Buford Highway NE, Atlanta, GA 30341-3717 (USA)

muk1@cdc.gov 
Table 1. Common communication challenges about the role of genomics in public health and efforts to address them

\begin{tabular}{lll}
\hline Communication challenges & Addressing the challenge & CDC communication efforts \\
\hline $\begin{array}{l}\text { Communicating that using genomics to } \\
\text { assess rare diseases can have an impact on } \\
\text { public health }\end{array}$ & $\begin{array}{l}\text { Diseases may be individually rare but are } \\
\text { collectively common, with rare diseases affecting } \\
25 \text { million people in the USA } \\
\text { Genomics can help detect these rare diseases, } \\
\text { which affect large portions of the population }\end{array}$ & $\begin{array}{l}\text { Maintain up-to-date database of publications and } \\
\text { resources for rare diseases } \\
\text { Develop publications highlighting value and } \\
\text { importance of public health response } \\
\text { Maintains website and other resources highlighting } \\
\text { public health impact of newborn screening }\end{array}$ \\
$\begin{array}{lll}\text { Providing evidence that genetic factors } \\
\text { can add important information to } \\
\text { environmental, behavioral, and social } \\
\text { determinants of health }\end{array}$ & $\begin{array}{l}\text { Research suggests that most diseases involve } \\
\text { complex interactions between genes, environment, } \\
\text { and behaviors }\end{array}$ & $\begin{array}{l}\text { Emphasize the importance of gene-environment } \\
\text { interaction in communication efforts }\end{array}$ \\
$\begin{array}{l}\text { Communicating that genetic factors can } \\
\text { increase the impact of public health } \\
\text { programs }\end{array}$ & $\begin{array}{l}\text { Nonmodifiable risk factors such as genetics could } \\
\text { be useful to better target clinical and public health } \\
\text { interventions }\end{array}$ & $\begin{array}{l}\text { Develop and promote FHH tools as an example of a } \\
\text { nonmodifiable risk factor, which can provide valuable } \\
\text { information to identify those at higher disease risk }\end{array}$ \\
$\begin{array}{l}\text { Addressing the concern that genomics is } \\
\text { not ready for clinical practice }\end{array}$ & $\begin{array}{l}\text { There are strong support and evidence for Tier 1 } \\
\text { genomics applications to be used at the population } \\
\text { level, with 2 million people in the USA having a } \\
\text { Tier 1 condition and being unaware of their risk }\end{array}$ & $\begin{array}{l}\text { Support public health initiatives to identify the 2 } \\
\text { million people who are at risk for Tier 1 genomics } \\
\text { applications }\end{array}$ \\
$\begin{array}{l}\text { Communicating that genomics is valuable } \\
\text { beyond health care and can be integrated } \\
\text { into public health programs }\end{array}$ & $\begin{array}{l}\text { Collaborating across sectors can help optimally } \\
\text { implement validated genomic applications }\end{array}$ & $\begin{array}{l}\text { Measure impact of public health programs using } \\
\text { genetics (e.g., Tier 1 applications) }\end{array}$ \\
\hline
\end{tabular}

CDC, Centers for Disease Control and Prevention; FHH, family health history.

lational gap remains, which currently limits the uptake and impact of genomics-based approaches and evidencebased recommendations to improve population health [4-7]. While there are many factors that may be impeding progress in translating genomic discoveries into population health benefit, one important opportunity is to provide widespread, clear communication to the public, researchers, and practitioner about the role genomics can have in improving population health $[4,8,9]$.

Based on interactions over 2 decades with partners, stakeholders, and state public health programs, we outline communication challenges identified by the Office of Genomics and Precision Public Health (OGPPH) at the Centers for Disease Control and Prevention (CDC). These communication challenges are important to address in order to harness the contributions of genomics in public health [10]. The 5 communication challenges addressed in this commentary include: (1) communicating that using genomics to assess rare disease can have an impact on public health, (2) providing evidence that genetic factors can add important information to environmental, behavioral, and social determinants of health, (3) communicating that although genetic factors are nonmodifiable, they can be used to guide public health programs and communication strategies, (4) addressing the concern that genomics is not ready for clinical practice, and (5) communicating that genomics is valuable beyond the domain of health care and can be integrated as part of public health programs. In this commentary, we elaborate on these challenges and discuss specific communication efforts the OGPPH has undertaken to address them (Table 1) $[4,8,9]$.

\section{Communication Challenge 1: Communicating that Using Genomics to Assess Rare Diseases Can Have an Impact on Public Health}

While individually rare, rare diseases collectively affect over 25 million people with more than 7,000 known rare diseases in the USA [11]. It may take several years for many patients to receive a correct diagnosis, with the current average between 5 and 7 years [11]. The average cost of drugs approved for rare diseases is USD 118,820 per patient each year [12]. Many rare disorders have genetic origins, which are increasingly uncovered through the use of genome sequencing [11]. Thus, a genome sequencing approach could help reduce the high cost of the diagnostic odyssey for patients and family in terms of both time and money and allow for more tailored treatment.

To identify publications and other resources on rare diseases, OGPPH maintains a public health genomics 
knowledge base (PHGKB) on rare diseases $[13,14]$. The database is continuously updated with published literature and resources that address the translation of genomics and precision health discoveries into improved health care and disease prevention for people with rare diseases [15]. Additionally, a 2017 CDC paper highlighted the value and importance of developing a public health response to rare diseases that includes surveillance, applied research, and ensuring appropriate health care and social services to affected individuals and their families $[16,17]$.

One of the most notable public health successes related to rare diseases, newborn screening, allows for earlier detection and treatment of certain rare disorders, resulting in improved health outcomes $[18,19]$. The Genomics and Precision Health Weekly Update includes a section on newborn screening [20], and a search of the CDC PHGKB identified over 1,500 published resources related to newborn screening [15]. CDC also maintains a website on newborn screening, which includes links to personal stories by families affected by newborn screening conditions $[18,19]$. Additionally, regular communication about newborn screening through online materials and social media is designed to help the public understand the role of laboratories and needs for newborn screening to detect and intervene early in order to prevent early death and disability $[18,19,21]$.

Communication Challenge 2: Providing Evidence that Genetic Factors Can Add Important Information to

Environmental, Behavioral, and Social Determinants of Health

A commonly held belief is that genetic information does not provide additional valuable information to inform public health efforts. Although macro-level factors such as environment, behaviors, and social factors are important determinants of health, most diseases result from the combined effects of multiple determinants, including genetics [22]. Indeed, genomics can play a role in better understanding the environmental contributors to disease. For example, Mendelian randomization is an approach that uses genetic variants related to both modifiable risk factors and health outcomes to demonstrate causal relationships between the two [23].

OGPPH seeks to educate audiences about the role that both genetic and environmental factors can play in determining health outcomes. One example of efforts to communicate about this topic includes a popular public-facing blog, "Shall We Have Pie or Stew" that illustrates the interplay of genetic versus environmental factors [24]. The blog post describes the contribution of genetic and

Communication about the Role of Genomics in Public Health environmental contributors to disease outcomes, using an easy to understand metaphor that demonstrates how disease outcomes are a complex medley of factors. Additionally, the PHGKB includes a wide range of "hot topics" that captures the latest information about publications related to genetics and environmental factors.

\section{Communication Challenge 3: Communicating that} although Genetic Factors Are Nonmodifiable, They Can Increase the Impact of Public Health Programs and Communication Strategies

The OGPPH has also sought to address the misunderstanding that genetic factors are nonmodifiable and thus do not deserve attention in public health programs. However, it is common for public health research and practice to evaluate for nonmodifiable factors such as age, race/ ethnicity, and sex, which are regularly collected and analyzed in public health programs. Understanding differences in health outcomes based on these variables can help address underlying determinants of health and adapt interventions to meet specific population health needs. Likewise, genetic factors can help target interventions such as early or more frequent cancer screening and genetic counseling and testing [25]. A prime example is the inclusion of family health history (FHH) in evidencebased guidelines supporting the identification of those at increased risk, such as the USPSTF recommendation, "BRCA-Related Cancer: Risk Assessment, Genetic Counseling, and Genetic Testing" [2].

Knowing and acting on $\mathrm{FHH}$ information can prevent disease for individuals and family members, as discussed in the OGPPH blog post, "Family Health History is a Non-Modifiable Risk Factor - or is it?" [26] Since September 2018, OGPPH has hosted "My Family Health Portrait" a FHH collection tool geared toward the general public. Between September 2018 and November 11, 2019, My Family Health Portrait received over 2 million page views. $\mathrm{CDC}$ also has a web page for $\mathrm{FHH}$ outlining the importance of family history by life stage [27]. In addition, specific CDC web pages feature the role of FHH in conditions such as HBOC, hereditary colorectal cancer, and heart disease [28-30].

For many years, the US Surgeon General declared Thanksgiving to be National Family History Day, demonstrating the value of $\mathrm{FHH}$ as a tool for public health [31]. CDC continues to work with the National Human Genome Research Institute and other partners to promote family history on Thanksgiving Day. In 2016 and 2017, OGPPH used a message amplifying service to promote social media messages on Twitter and Facebook, 
reaching over 1 million users in 2016 and over 3 million users in 2017. In 2018 and 2019, OGPPH created FHH graphics and social media messages for posting on CDC social media channels, including Twitter (@CDC_ eHealth), Facebook, Instagram, and Pinterest.

\section{Communication Challenge 4: Addressing the Concern} that Genomics Is Not Ready for Clinical Practice

A fourth communication challenge is demonstrating that there is sufficient evidence to support integration of genomics into clinical practice. To address this challenge, the OGPPH has developed a tiered system to classify genomic applications according to the level of evidence supporting their use. Tier 1 applications have sufficient evidence of clinical validity and utility along with a guideline for use in practice, and are therefore ready for clinical practice [32,33]. OGPPH has focused many of its efforts on Tier 1 applications related to 3 genetic conditions, HBOC syndrome, LS, and FH, which together affect between 1 and 3 million people in the USA [3]. Efforts to disseminate information about Tier 1 applications include the development of the Tier 1 Genomic Applications Tool Kit for Public Health Departments [34]. This tool kit was designed to help state health agencies interested in implementing HBOC-, LS-, and FH-related activities and includes customizable materials, fact sheets, guideline summaries, letters to families, and an educational slide set for HBOC and LS $[35,36]$. Specific web pages are dedicated to HBOC and LS [37, 38]. CDC also publishes visual abstracts that summarize key findings from publications related to these topics [39]. Furthermore, PHGKB includes the Tier-Classified Guidelines Database, which provides the appropriate tier classification for selected guidelines [40]. Finally, CDC's Bring Your Brave campaign encourages women under 45 to share stories about their experience with breast cancer. The campaign focuses on motivating women to learn their family history of breast and ovarian cancers, educates women on the risk factors for breast cancer, empower women to discuss their risk for breast cancer, and promotes healthy lifestyles and awareness about breast health [41].

Communication Challenge 5: Communicating that

Genomics Is Valuable beyond the Domain of Health

Care and Can Be Integrated as Part of Public Health

Programs

The final challenge is communicating that genomics is not only important for health care but also public health practice $[8,9]$. While many genomic applications are in- creasingly being integrated into medical care, genomic applications are available that are relevant to public health, including cascade screening of family members who may be at an increased risk of developing HBOC, LS, or $\mathrm{FH}$ and promoting insurance coverage for genetic counseling and testing by clarifying how to reimburse for genetic services [42]. Clinical and public health partnerships will be essential to ensure that implementation of genomics applications benefits the entire population [43, 44].

The OGPPH has supported conversations about ways that genomics can support public health and how it can be applied outside of clinical settings. One effort included a conversation with opposing viewpoints about whether public health can benefit from genomics. Since the initial launch of the video in 2016, the conversation has been viewed by 1,344 individuals. Reducing the misconception that genomics does not belong in public health is perhaps the most valuable aspect of the OGPPH communication strategy. The goal of this communication strategy is to continue providing examples of ways that the 2 fields can coordinate and work together to improve population health [44].

One specific emerging example of how genomics is relevant outside of clinical practice is through pathogen genomics. While the use of human genomics approaches in public health has been limited, pathogen genomics approaches have been widely embraced by public health programs and are the focus of the CDC advanced molecular detection (AMD) initiative. This initiative combines traditional epidemiology with next-generation sequencing and bioinformatics to help improve understanding, prevention, and control of infectious disease. Next-generation sequencing is being used for diagnosing infections (e.g., legionella and mycoplasma pneumonia), investigating outbreaks (e.g., listeria and Ebola virus), describing transmission patterns (e.g., tuberculosis and hepatitis), monitoring antimicrobial resistance (e.g., Neisseria gonorrhea), and developing interventions and vaccines (e.g., influenza and polio eradication) [45]. CDC hosts infectious diseases PHGKB and the Genomics and Precision Health Weekly Update includes AMD Weekly Clips, which provides AMD-related articles, news, events, and tools [46].

\section{Moving toward Public Health Genomics through \\ Targeted Communication}

To help address the 5 communication challenges described, the OGPPH works with key stakeholders including public health programs and partners (e.g., states, 
Table 2. Priority areas for addressing the role of genetics in public health, specific steps, and communication opportunities for public health moving forward

\begin{tabular}{|c|c|c|c|}
\hline Priority & General actions & Specific steps & $\begin{array}{l}\text { Communication and dissemination } \\
\text { opportunities for CDC and other } \\
\text { stakeholders }\end{array}$ \\
\hline \multirow{3}{*}{$\begin{array}{l}\text { Serving as the honest broker } \\
\text { for emerging genomic } \\
\text { applications to consumers, } \\
\text { providers, and policy makers }\end{array}$} & \multirow{3}{*}{$\begin{array}{l}\text { Conducting and sponsoring } \\
\text { knowledge synthesis and } \\
\text { evidence recommendations on } \\
\text { appropriate use }\end{array}$} & $\begin{array}{l}\text { Use evidence-based methods to } \\
\text { determine utility and validity of } \\
\text { genomic applications }\end{array}$ & $\begin{array}{l}\text { Share information about how evidence is } \\
\text { classified in each Tier }\end{array}$ \\
\hline & & $\begin{array}{l}\text { Classify genomic applications into } \\
\text { Tiers } 1-3\end{array}$ & $\begin{array}{l}\text { Use of existing public-facing PHGKB to } \\
\text { classify into Tiers }\end{array}$ \\
\hline & & $\begin{array}{l}\text { Disseminate information for policy, } \\
\text { research, and practice }\end{array}$ & $\begin{array}{l}\text { Creating user-friendly information that } \\
\text { can be disseminated through website, } \\
\text { blog, and Twitter }\end{array}$ \\
\hline \multirow[t]{2}{*}{$\begin{array}{l}\text { Implementing evidence-based } \\
\text { genomic applications and } \\
\text { discouraging use of invalidated } \\
\text { applications }\end{array}$} & \multirow[t]{2}{*}{$\begin{array}{l}\text { Implementing multilevel } \\
\text { interventions }\end{array}$} & $\begin{array}{l}\text { Develop and implement model } \\
\text { programs using multilevel intervention }\end{array}$ & $\begin{array}{l}\text { Provide examples of successful model } \\
\text { programs; support efforts to } \\
\text { communicate about success of } \\
\text { programs; and disseminate best practices }\end{array}$ \\
\hline & & $\begin{array}{l}\text { Programs will encourage Tier 1, } \\
\text { promote informed decision-making } \\
\text { for Tier 2, discourage Tier } 3\end{array}$ & $\begin{array}{l}\text { Continue supporting applications and } \\
\text { provide timely and useful evidence about } \\
\text { applications }\end{array}$ \\
\hline \multirow[t]{3}{*}{$\begin{array}{l}\text { Evaluating impact that } \\
\text { genomics could add to public } \\
\text { health interventions }\end{array}$} & \multirow[t]{3}{*}{$\begin{array}{l}\text { Evaluating benefits and harms } \\
\text { of public health programs in } \\
\text { subgroups of population using } \\
\text { genomics tools and precision } \\
\text { public health approaches }\end{array}$} & $\begin{array}{l}\text { Measure outcomes, process indicators, } \\
\text { and value-added of genomic } \\
\text { applications to improve health }\end{array}$ & $\begin{array}{l}\text { Provide information to the public about } \\
\text { possible outcomes, process indicators, } \\
\text { and value-added of genomics } \\
\text { applications }\end{array}$ \\
\hline & & Inform knowledge synthesis & $\begin{array}{l}\text { Serve as a repository of information } \\
\text { related to genomics knowledge }\end{array}$ \\
\hline & & Evaluate programs & $\begin{array}{l}\text { Compile evaluations of genomics } \\
\text { programs and support evaluation efforts }\end{array}$ \\
\hline
\end{tabular}

CDC, Centers for Disease Control and Prevention; PHGKB, public health genomics knowledge base.

health systems, and providers), the public, and public health researchers to disseminate accurate and timely information about genomics. Specifically, the OGPPH seeks to identify evidence-based genomic applications, inform public health programs, clinical practice, researchers, and the general public, and integrate appropriate applications into public health programs and clinical practice. As described, the OGPPH supports a wide range of products to help disseminate messages about precision public health and reduce misconceptions. Specific products include public-facing website, weekly updates about genomics [47], blog posts about relevant and timely research topics [48], Twitter posts [49], and the PHGKB [15].

As we look ahead, there are many ways to build upon existing strategies to better align efforts to improve both translation of findings and engagement of public health practitioners, researchers, and the public about content related to genomics. Specifically, 3 priority areas have previously been identified for stakeholders and the CDC to support continued advancement of the precision public health agenda, which include (1) serving as an "honest broker" for emerging genomic applications to public health programs, consumers, providers, and policy makers, (2) implementing evidence-based genomic applications and discouraging use of unvalidated applications, and (3) evaluating the impact that genomics could add to public health interventions (Table 2) [50].

These priority areas and specific steps offer opportunities for CDC to continue efforts to overcome communication challenges and misunderstanding, along with other partners who are invested in advancing public health genomics. To date, most of the existing efforts undertaken by the OGPPH address the priority area of serving as an honest broker of information. Most notably, the OGPPH classifies evidence into Tiers and disseminates articles, updates, and tool kits related to the Tiers to the public, researchers, and practitioners. The other 2 prior- 
ity areas - the implementation of evidence-based genomic applications and evaluation of the impact of public health interventions - are largely outside of the purview of the OGPPH's communication initiatives. While OGPPH can continue to provide information to consumers, providers, and policy makers to support the implementation and evaluation of programs focused on genomics in public health, the execution of these programs largely lies within disease-specific public health programs. There are already a number of examples of programs that have successfully developed and evaluated multilevel genomic-based interventions to disseminate inherited risk information and implemented screening approaches in community settings (priority area 2) [5153]. These and other programs could be highlighted as part of ongoing communication efforts to support understanding of the role of genetics in public health. The OGPPH has the opportunity to support such initiatives and communicate about findings or synthesize evidence across programs; however, the key to continued success in translation of genomic discovery will be a combination of strong leadership in the field and continued collaboration across sectors. Continuing to promote and convey the success of public health genomics research and programs will help build support for ongoing initiatives.

\section{Conclusion}

Addressing communication challenges is crucial given how rapidly genomic discoveries are occurring and the uncertainty about their use in improving health and clinical practice. While acknowledging the excitement surrounding new scientific discoveries, providing consistent and reliable communication about opportunities for future public health genomics applications can help strengthen and promote a meaningful dialogue with key stakeholders and the implementation of evidence-based genomic applications. Future opportunities to advance genomics translation will rely on consistent, clear, and evidence-based messaging that can help not only address misconceptions but also heed calls to action $[54,55]$ to integrate evidence-based genomic applications into clinical and public health programs.

\section{Statement of Ethics}

No human subjects were included as part of this study.

\section{Conflict of Interest Statement}

The authors have no conflicts of interest to report.

\section{Funding Sources}

The authors did not receive any funding.

\section{Author Contributions}

Caitlin G. Allen oversaw the development and writing of this manuscript. Ridgley Fisk Green, Scott Bowen, and Dave Dotson contributed to writing the manuscript and editing and provided final approval. Wei Yu provided data used in the manuscript and contributed to editing and final approval of the manuscript. Muin J. Khoury conceptualized the manuscript and contributes to writing and editing and final approval.

\section{References}

1 U.S. Department of health and human services, 2020 topics and objective: genomics. 2015.

2 U.S. Preventive Services Task Force. Final recommendation statement: BRCA-related cancer: risk assessment, genetic counseling, and genetic testing. 2019. Available from: https:// www.uspreventiveservicestaskforce.org/ Page/Document/RecommendationStatementFinal/brca-related-cancer-risk-assessment-genetic-counseling-and-genetic-testing1.

3 Khoury MJ, Bowen MS, Clyne M, Dotson WD, Gwinn ML, Green RF, et al. From public health genomics to precision public health: a 20-year journey. Genet Med. 2018;20(6):57482.
4 Best A, Hiatt RA, Norman CD. Knowledge integration: conceptualizing communications in cancer control systems. Patient Educ Couns. 2008;71(3):319-27.

5 Leavitt M. Medscape's response to the Institute of medicine report: crossing the quality chasm: a new health system for the 21 st century. MedGenMed. 2001;3(2):2.

6 Chambers DA. Commentary: increasing the connectivity between implementation science and public health: advancing methodology, evidence integration, and sustainability. Annu Rev Public Health. 2018;39:1-4.

7 Khoury MJ, Clauser SB, Freedman AN, Gillanders EM, Glasgow RE, Klein WM, et al. Population sciences, translational research, and the opportunities and challenges for genomics to reduce the burden of cancer in the 21st century. Cancer Epidemiol Biomarkers Prev. 2011;20(10):2105-14.

8 Chowkwanyun M, Bayer R, Galea S. "Precision" public health: between novelty and hype. N Engl J Med. 2018;379(15):1398-400.

9 Galea S, Abdalla SM. Precision medicine approaches and the health of populations: study design concerns and considerations. Perspect Biol Med. 2018;61(4):527-36.

10 Centers for Disease Control and Prevention. Five misconceptions about the role of genomics in public health. 2016. Available from: https://blogs.cdc.gov/genomics/2016/07/13/ five-misconceptions/. 
11 Valdez R, Ouyang L, Bolen J. Public health and rare diseases: oxymoron no more. Prev Chronic Dis. 2016;13:13E05.

12 Hesselgrave BL. Helping to manage the high cost of rare diseases. Manag Care Q. 2003; 11(1):1-6.

13 Centers for Disease Control and Prevention. Introducing the rare diseases genomics and precision health knowledge base. 2019. Available from: https://blogs.cdc.gov/genomics/2019/04/04/introducing-the-rare-diseases/.

14 Centers for Disease Control and Prevention. Rare disease. 2019

15 Centers for Disease Control and Prevention. Public health genomics and precision health knowledge base (v5.9). 2019. Available from: https://phgkb.cdc.gov/PHGKB/phgHome. action? action=home.

16 Valdex R, Grosse SD, Khoury MJ. The need for a next-generation public health response to rare diseases. 2017. Available from: https:// blogs.cdc.gov/genomics/2017/02/08/theneed-for-a-next-generation/.

17 Valdez R, Grosse SD, Khoury MJ. The need for a next-generation public health response to rare diseases. Genet Med. 2016;19(5):48990.

18 Prevention., C.f.D.C.a., Newborn Screening Portal. 2019.

19 Centers for Disease Control and Prevention, CDC's Newborn Screening Program: Role of Laboratories. 2019.

20 Centers for Disease Control and Prevention. Genomics and precision health weekly update. 2020. Available from: https://www.cdc. gov/genomics/update/current.htm.

21 Centers for Disease Control and Prevention. Newborn screening for severe combined immune deficiency (SCID) saves lives and money: a cost-effective public health strategy. 2016. Available from: https://blogs-origin. cdc.gov/genomics/2016/03/15/scid/.

22 Krieger N. Theories for social epidemiology in the 21st century: an ecosocial perspective. Int J Epidemiol. 2001;30(4):668-77.

23 Davies NM, Holmes MV, Davey Smith G. Reading Mendelian randomisation studies: a guide, glossary, and checklist for clinicians. BMJ. 2018;362:601.

24 Centers for Disease Control and Prevention. Shall we have pie or stew? 2011. Available from: https://blogs.cdc.gov/genomics/2011/ 08/11/shall-we-have-pie-or-stew/.

25 Centers for Disease Control and Prevention Family health history and the BRCA1 and BRCA2 genes. 2017. Available from: https:// www.cdc.gov/genomics/disease/breast_ovarian_cancer/fam_hist_genes.htm.

26 Green RF. Family health history is a nonmodifiable risk factor- or is it? 2014. Available from: https://blogs.cdc.gov/genomics/2014/11/13/family-health-history/.
27 Centers for Disease Control and Prevention. Family health history. 2020. Available from: https://www.cdc.gov/genomics/famhistory/ index.htm.

28 Centers for Disease Control and Prevention, hereditary breast and ovarian cancer: family health history. 2017.

29 Centers for Disease Control and Prevention, hereditary colorectal (colon) cancer family health history. 2018.

30 Centers for Disease Control and Prevention, genomics and precision health does heart disease run in your family? 2020.

31 Centers for Disease Control and Prevention. Happy thanksgiving: collect and act on your family health history. 2016. Available from: https: //blogs-origin.cdc.gov/genomics/2016/ 11/21/happy-thanksgiving/.

32 Centers for Disease Control and Prevention. Tier 1 genomics applications and their importance to public health. 2014. Available from: https://www.cdc.gov/genomics/implementation/toolkit/tier1.htm.

33 Dotson WD, Douglas MP, Kolor K, Stewart AC, Bowen MS, Gwinn M, et al. Prioritizing genomic applications for action by level of evidence: a horizon-scanning method. Clin Pharmacol Ther. 2014;95(4):394-402.

34 Centers for Disease Control and Prevention, Tier 1 Genomic Applications Toolkit for Public Health Departments. 2014.

35 Centers for Disease Control and Prevention. Tools for bidirectional cancer registry reporting to identify individuals at risk for lynch syndrome. 2017. Available from: https:// www.cdc.gov/genomics/implementation/ toolkit/lynch_4.htm.

36 Centers for Disease Control and Prevention. Tools for bidirectional cancer registry reporting to identify individuals at risk for hereditary breast and ovarian cancer syndrome. 2017.

37 Centers for Disease Control and Prevention. Hereditary breast and ovarian cancer. 2020. Available from: https://www.cdc.gov/genomics/disease/breast_ovarian_cancer/index. htm.

38 Centers for Disease Control and Prevention. Lynch syndrome. 2020. Available from: https://www.cdc.gov/genomics/disease/ colorectal_cancer/lynch.htm.

39 Centers for Disease Control and Prevention. Visual abstracts. 2019. Available from: https:// www.cdc.gov/genomics/visual/visual_abstract.htm.

40 Centers for Disease Control Prevention. Tier table database. 2018. Available from: https:// phgkb.cdc.gov/PHGKB/topicStartPage.action.

41 Centers for Disease Control and Prevention. Bring your brave. 2019. Available from: https://www.cdc.gov/cancer/breast/young women/bringyourbrave/about.htm.
42 Institute, N.H.G.R. Coverage adn reimbursement. 2019. Available from: https://www.genome.gov/about-genomics/policy-issues/ Coverage-Reimbursement-of-Genetic-Tests.

43 Allen CG, Fohner AE, Landry L, Paul J, Smith SG, Turbitt E, Roberts MC, et al. Early career investigators and precision public health. Lancet. 2019 Aug 3;394(10196):382-3.

44 Allen CG, Fohner AE, Landry L, Paul JL, Smith SG, Turbitt E, et al. Perspectives from early career investigators who are "staying in the game" of precision public health research. Am J Public Health. 2019 Sep;109(9):1186-7.

45 Centers for Disease Control and Prevention, advanced molecular detection (AMD) and response to infectious disease outbreaks. 2019.

46 Centers for Disease Control and Prevention. Infectious disease PHGKB. 2020. Available from: https://phgkb.cdc.gov/PHGKB/ specificPHGKB.action?topic=Infectious $\% 20$ diseases\&amp;query=home.

47 Centers for Disease Control and Prevention. Public health genomics weekly updates. 2019. Available from: https://www.cdc.gov/genomics/update/current.htm.

48 Centers for Disease Control and Prevention. Public health genomics: genomics and precision health blog. 2019. Available from: https:// www.cdc.gov/genomics/update/current.htm.

49 Centers for Disease Control and Prevention, CDC Genomics Twitter. 2019.

50 Khoury MJ, Bowen MS, Burke W, Coates RJ, Dowling NF, Evans JP, et al. Current priorities for public health practice in addressing the role of human genomics in improving population health. Am J Prev Med. 2011; 40(4):486-93.

51 Rahm AK, Cragun D, Hunter JE, Epstein MM, Lowery J, Lu CY, et al. Implementing universal Lynch syndrome screening (IMPULSS): protocol for a multi-site study to identify strategies to implement, adapt, and sustain genomic medicine programs in different organizational contexts. BMC Health Sery Res. 2018;18(1):824

52 Allen CG, Peterson S, Khoury MJ, Brody LC, McBride CM. A scoping review of social and behavioral science research to translate genomic discoveries into population health impact. Transl Behav Med. 2020 Sep 9;ibaa076.

53 Bowen DJ, Hay J, Meischke H, Mayer JA, Harris-Wai J, Burke W. Randomized trial of a web-based survivor intervention on melanoma prevention behaviors of first-degree relatives. Cancer Causes Control. 2019 Mar; 30(3):225-233.

54 Khoury MJ, Iademarco MF, Riley WT. Precision public health for the era of precision medicine. Am J Prev Med. 2016;50(3):398401

55 Chambers DA, Feero WG, Khoury MJ. Convergence of implementation science, precision medicine, and the learning health care system: a new model for biomedical research. JAMA. 2016;315(18):1941-2.
Communication about the Role of Genomics in Public Health
Public Health Genomics 2021;24:67-73 